\title{
Greenhouse cultivation of Serrano pepper (Capsicum annuum var. Acuminatum): dry hydroponics
}

\author{
Velázquez-Carmona, Miguel-Ángel ${ }^{1 *}$; Méndez-Arenas, Raquel $^{2}$; Valerio Cárdenas, Gintya ${ }^{1}$; \\ De la Cruz-Burelo, Patricia ${ }^{1}$; Silíceo-Rodríguez María L. ${ }^{3}$ \\ 1 División Académica de Ciencias Básicas e Ingenierías (DESICA), Universidad Popular de la Chontalpa, H. \\ Cárdenas, Tabasco, México, C. P. 86553. \\ 2 Coordinación de Investigación y Posgrado, Maestría en Desarrollo Sustentable (MDS), Universidad Popular \\ de la Chontalpa, H. Cárdenas, Tabasco, México, C. P. 86553. \\ 3 El colegio de Veracruz, Carrillo Puerto No. 26, Zona Centro, Xalapa, Veracruz, C.P. 91000. \\ * Correspondence: m.velazquez@upch.mx
}

Citation: Velázquez-Carmona, M. Á., Méndez-Arenas, R., Valerio Cárdenas, C., De la Cruz-Burelo, P., \& SilíceoRodríguez M. L. (2021). Greenhouse cultivation of Serrano pepper (Capsicum annuum var. Acuminatum): dry hydroponics. Agro Productividad. https:// doi.org/10.32854/agrop.v14il1.2018

Editor in Chief: Dr. Jorge Cadena Iñiguez

Received: April 30, 2021. Accepted: October 21, 2021. Published on-line: November 26, 2021.

This work is licensed under a Creative Commons Attribution-NonCommercial 4.0 International license.

\begin{abstract}
Objective: To produce Serrano peppers using a new cultivation technique that mixes the best of hydroponic cultivation and traditional cultivation.

Design/methodology/approach: We set up a growing system where the Serrano pepper grew from seedling to its full-fledged state, in a growbag containing sand (as support material), potassium polyacrylate (as water retention material), and a nutrient solution for vegetable gardens, under greenhouse conditions. The humidity level of the growbag is controlled by adding as much water with nutrient solution as needed. This technique has generated $100 \%$ harvestable plants (total: 20 plants); more than $90 \%$ of the water can be saved in comparison to regular and hydroponic cultivation.

Results: Once the harvest began, at least $22.857 \mathrm{~kg}$ of Serrano pepper were obtained in $3 \mathrm{~m}^{2}$ of soil in a system with a pyramidal structure in which the 20 plants were placed. If we extrapolated this data, approximately 93,000 kg of Serrano pepper could be harvested from a 1 ha system.

Study Limitations/implications: This technique tries to tackle the water access limitations that may exist in some areas of Mexico. However, it does not mitigate the initial costs of a greenhouse system. Nevertheless, this technique can be reused up to 10 times without requiring maintenance.

Findings/conclusions: Experience has shown that hydroponic crops are truly profitable, despite their vast water requirements, which is precisely what prevents their global expansion. However, our modification of this method saves more than $90 \%$ of the water, using potassium polyacrylate as a retention agent and sand as a support material. Therefore, this technique could be implemented even in places where water is scarce.
\end{abstract}

Keywords: Dry hydroponics, potassium polyacrylate, Serrano pepper.

\section{INTRODUCTION}

Hydrogels are cross-linked macromolecular hydrophilic polymer chains capable of absorbing water or aqueous fluids. The most commercially successful hydrogels are superabsorbent polymers, also known as SAP (Zhouriaan-Mehr et al., 2010), which generally can absorb around 200-350 times their weight in distilled water, increasing proportionally in size. 
An osmosis process delivers up to $95 \%$ of the retained water to the plant; its benefits include: a notable delay in wilting under hostile conditions; a greater growth of the species; and a tendency to decrease the volume of water required to maintain a crop. Hydrogels are being used in some crops, to provide plants with the water that their development requires during dry seasons - reducing up to $75 \%$ of the water used for irrigation - and to obtain other benefits - such as increasing the productivity and quality of the crops (Anonymous, 2008). The application of hydrogels in agricultural crops was first studied in Mexico by the agronomist Sergio Rico, who realized that, if water was added to a polymer powder, the resulting gel would be capable of absorbing up to 500 times its weight. This gel could be deposited next to the root of the plants, providing them the water they need for their development (Anonymous, 2021).

Competition for natural resources (soil and water) is intensifying. Climate change reduces the resistance of production systems and contributes to the degradation of natural resources. The expansion of the agricultural frontier for food production has a high environmental impact, as a result of the deforestation of forests, contributing significantly to climate change, as well as to the loss of soil fertility and production potential. From a sustainability perspective, controlled spaces influence the enhancement of plant production, contributing to the conservation of the soil and natural resources (FAO, 2020).

The objective of this research was to evaluate the water retention capacity of hydrogel in greenhouse cultivation, seeking an alternative that reduces the use of irrigation water in horticultural crops and offering a solution to grow crops in semi-arid, arid or infertile areas, as well as generating crops in confined spaces to make the most of small areas.

\section{MATERIALS AND METHODS}

The study site is located in La Venta, Huimanguillo, Tabasco, Mexico (18 $06^{\circ} 43^{\prime \prime} \mathrm{N}$, $94^{\circ} 02^{\prime} 24$ ” W), at the Instituto Tecnológico Superior de Villa La Venta, which has a hothumid climate, a $30^{\circ} \mathrm{C}$ average temperature, and a 2000-3000 $\mathrm{mm}$ annual precipitation (Climatología, 2021). The dry hydroponics technique proposed in this work was developed under greenhouse conditions. Temperatures were taken inside and outside the greenhouse with high precision Hanna Checktemp ${ }^{\circledR} 1$ thermometers. Moisture was measured with a CONDUCTRONIC PG18 hygro-thermometer. A Hanna potentiometer was used to measure the $\mathrm{pH}$. The nutrient solution and potassium polyacrylate were used without modifications - just as they were received from the commercial provider-; recycling materials were used to complement commercially available materials.

The structure of the hydroponics technique was modified for this research. Traditionally large amounts of water are used regardless of the variation of the method used, but emphasis is made on flooding and drainage techniques, as well as root-in-water techniques — such as Nutrient Film Technique (NFT) and Deep Water Culture (DWC), described by Gravital Agency (2021). The technique was developed in a greenhouse with a curved roof and mesh walls; this type of greenhouse has a high solar energy transmittance (Agrovit, 2021). 
A $3-\mathrm{m}^{2}$ pyramidal structure $(1.5 \mathrm{~m}$ wide $\times 2 \mathrm{~m} \mathrm{long})$ was built to place 20 growbags with one Serrano pepper plant per bag. Each growbag contained $50 \%$ of sand that had been previously mixed with potassium polyacrylate $4 \mathrm{~g}$ of SAP with $5 \mathrm{Kg}$ of sand and $1 \mathrm{Kg}$ of gravel). The seeds were extracted from a commercially available stock and were prepared for germination in agricultural foam. Once the seedlings were obtained, they were integrated into the dry hydroponics system, as part of which they were watered with a nutrient solution for vegetable gardens, the same solution used in traditional hydroponic systems. As a reference system, 20 Serrano pepper seedlings were placed in 20-L jugs with a nutrient solution that was renewed every week ( 1 seedling per jug).

The first tests were carried out in the experimental area of the Universidad Popular de la Chontalpa (UPCH), where 150 Serrano pepper seeds were sown in three different agricultural foam systems (Figure 1a, b). We decided not to buy standard seeds, because ideally this project should be applied in all the socioeconomic scales in the area, which include small households and little or no investment.

The germination of the seeds was $100 \%$ successful. This allowed us to establish a seedling management protocol, because an extremely hot climate can be very aggressive if the control system is neglected.

\section{Structure of the dry hydroponics system}

The experimental design was installed in 4 spatial distribution lines, on a $1.5 \mathrm{~m}(\mathrm{~h}) \times$ $2 \mathrm{~m}(\mathrm{l}) \times 1.5 \mathrm{~m}(\mathrm{w})$ pyramidal structure (Figure 2a). The experimental system included a total of 20 plants (Figure $2 b$ ).

\section{Hydroponic system structure (reference system)}

Recyclable materials (20-L jugs) were used for the hydroponic system. A 10-cm hole was cut on one side to introduce water and plants. They were previously disinfected with chlorine, detergent, and tap water. Subsequently, $20 \mathrm{~L}$ of water were poured in each jug. Twenty $\mathrm{ml}$ of nutrients for vegetable gardens were used per jug. A 3-L bottle cut in half -in
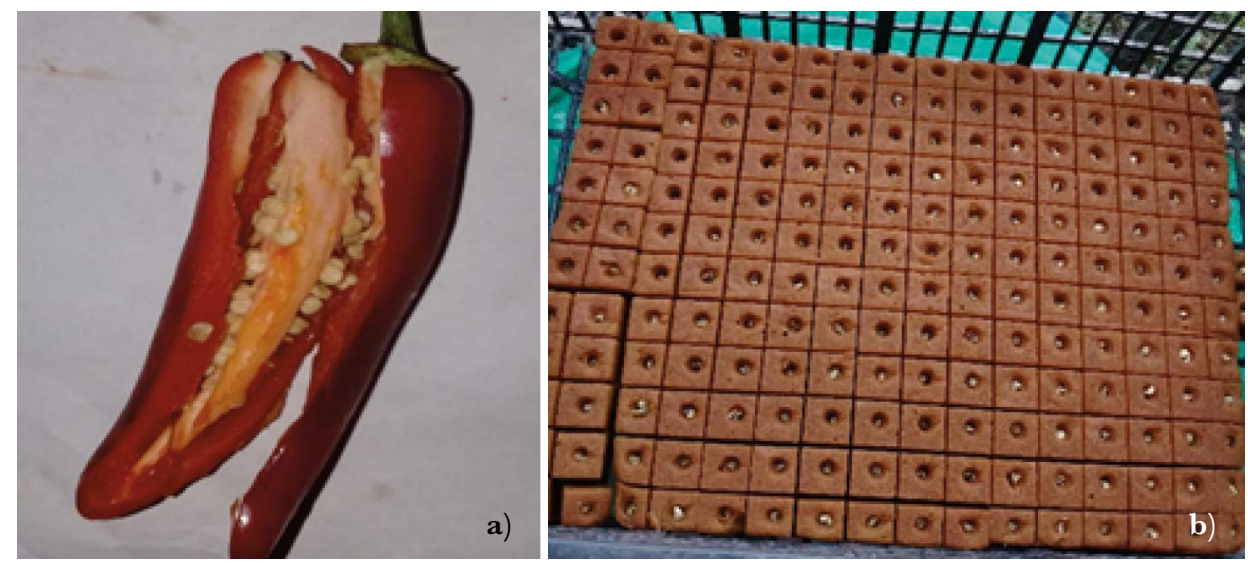

Figure 1. a) Seeds obtained from commercially-available fruits, b) Seed germination. 

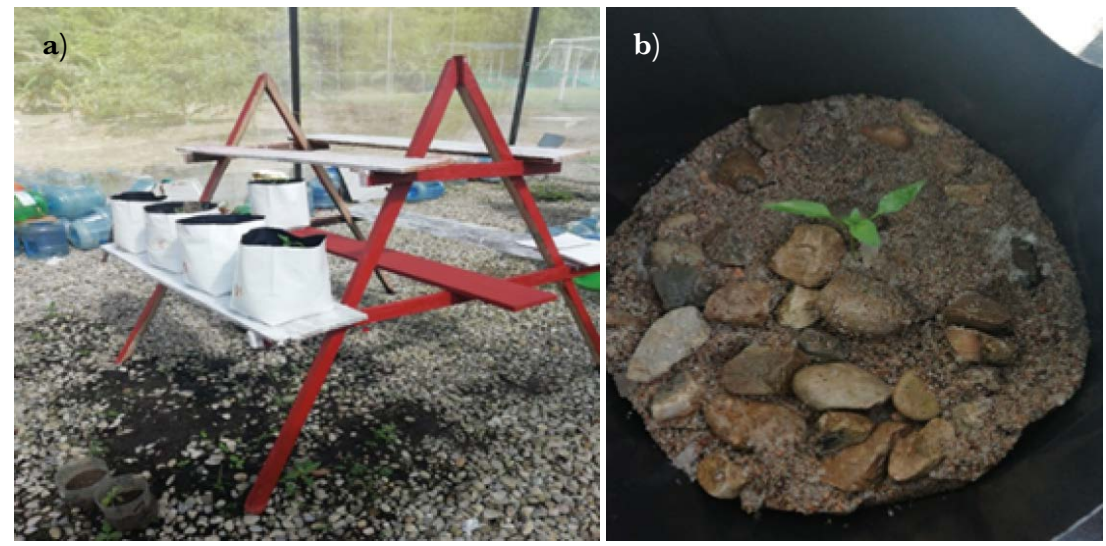

Figure 2. a) Pyramidal structure, b) Transplanted seedlings.

which a small hole was made in the lower part - was used to hold the plant. A total of 20 repetitions were carried out.

In other words, 10 3-L PET bottles were reused; they were cut in half (Figure 3a); a 2-cm hole was made in the lower part of the bottle to introduce the plant and to function as its support; finally, it was inserted in the jug that contained the abovementioned mixture (Figure 3b); the root floated on its surface.

\section{RESULTS AND DISCUSSION}

Irrigation is the most important part of the dry hydroponics technique. Table 1 shows that $20 \mathrm{~L}$ of the nutrient solution were added to the entire system every 4 weeks $(1 \mathrm{~L}$ per growbag).

The results were encouraging after the end of the growing and irrigation period, up to $98 \%$ of the water was saved. Only $60 \mathrm{~L}$ of nutrient solution were used to grow 20 plants, while the traditional hydroponics reference system spent an average of $264 \mathrm{~L}$ per week for 13 weeks (total: $3440 \mathrm{~L}$ ). One concern at this point is that, to maintain enough humidity

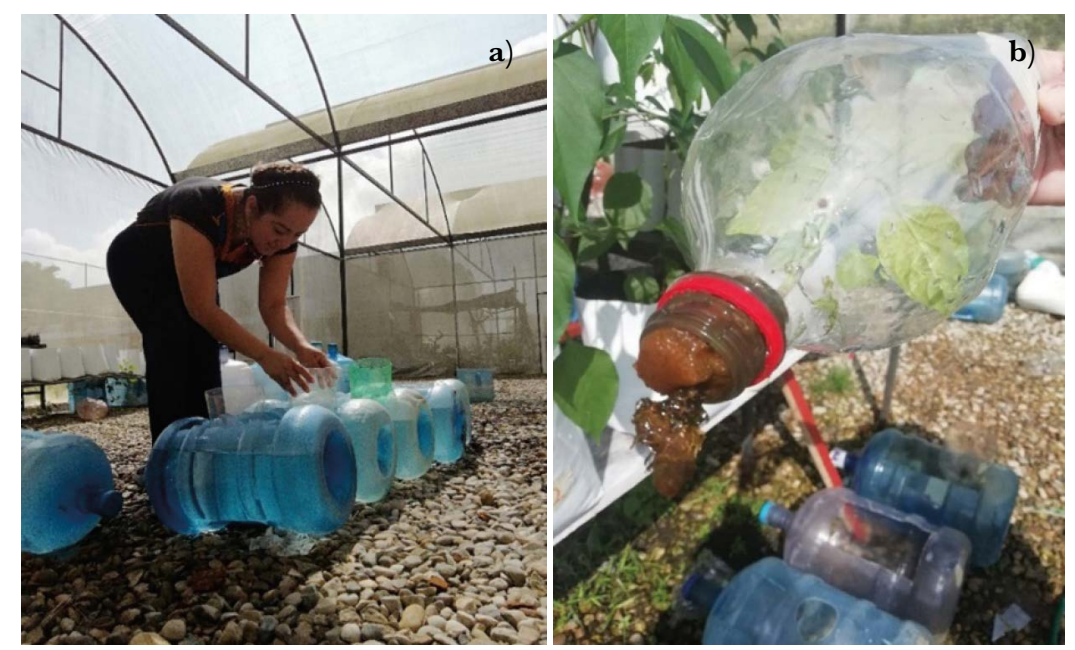

Figure 3. a) Section of the seedling support and b) Seedling in the support. 
Table 1. Irrigation plan for the dry hydroponics system and the reference system.

\begin{tabular}{c|c|c}
\hline \multirow{2}{*}{ Week } & Dry hydroponic & Hydroponic \\
\cline { 2 - 3 } & \multicolumn{2}{|c}{ Irrigation (L) } \\
\hline 1 & 20 & 400 \\
\hline 2 & & 400 \\
\hline 3 & & 400 \\
\hline 4 & 20 & 360 \\
\hline 5 & & 360 \\
\hline 6 & & 320 \\
\hline 7 & & 300 \\
\hline 8 & & 260 \\
\hline 9 & & 200 \\
\hline 10 & & 160 \\
\hline 11 & & 140 \\
\hline 12 & & 100 \\
\hline 13 & & 40 \\
\hline
\end{tabular}

for the healthy development of the plants, the average humidity measure should be $80 \%$ from the first day to the harvest. This is a major concern, since a hectare of traditional cultivation requires about 24,000 liters of water in a drip system - which is one of the most efficient systems (Horacio et al., 2010).

In this work, in addition to temperature and humidity, the $\mathrm{pH}$ of different parts of the growbag was measured. Both systems maintained a practically neutral $\mathrm{pH}$ of 6.73 and 6.77 for dry hydroponics and for the reference system, respectively. This is significant, because the Serrano pepper has a 5.5 and $7.5 \mathrm{pH}$ range in which it can develop without any problem (Robinson, 2014). Additionally, the color, leaf size, and stem of each plant were recorded in order to determine if water control had had any kind of impact on the plants. These measurements did not show any impact, only completely healthy plants. However, the reference system had yellowish leaves before the water changes. Therefore, we concluded that water control should be carried out in shorter periods, thus causing a greater water expenditure.

Before discussing harvest yield, we must mention that the harvest fruit seemed to be ready a couple of weeks before the average harvest time. Table 2 shows that three important harvest exercises took place: $22.85 \mathrm{~kg}$ of Serrano pepper were obtained.

The production in the dry hydroponics system obtained the expected result: implementing potassium polyacrylate in the inert system as a water retention agent provided the plants with the humidity they required for their development and production. Additionally, $100 \%$ of the plants achieved a successful development; this is a much better result than the one obtained by the plants of the hydroponic system of reference - of which only 2 out of 20 bore fruits, at the time of harvest. 
Table 2. Serrano pepper harvest record in a dry hydroponics system.

\begin{tabular}{|c|c|c|c|}
\hline \multirow{2}{*}{ Number } & HS1 harvest & HS2 harvest & HS3 harvest \\
\hline & \multicolumn{3}{|c|}{ Weight (g) } \\
\hline 1 & 612 & 340 & 329 \\
\hline 2 & 488 & 460 & 321 \\
\hline 3 & 700 & 315 & 356 \\
\hline 4 & 601 & 235 & 322 \\
\hline 5 & 597 & 399 & 221 \\
\hline 6 & 700 & 301 & 335 \\
\hline 7 & 620 & 220 & 202 \\
\hline 8 & 650 & 200 & 250 \\
\hline 9 & 470 & 345 & 307 \\
\hline 10 & 600 & 205 & 290 \\
\hline 11 & 500 & 532 & 357 \\
\hline 12 & 400 & 218 & 283 \\
\hline 13 & 350 & 430 & 337 \\
\hline 14 & 220 & 300 & 284 \\
\hline 15 & 300 & 242 & 263 \\
\hline 16 & 350 & 398 & 284 \\
\hline 17 & 180 & 444 & 227 \\
\hline 18 & 250 & 266 & 243 \\
\hline 19 & 460 & 609 & 691 \\
\hline 20 & 322 & 701 & 425 \\
\hline Partial & 9370 & 7160 & 6327 \\
\hline Total & \multicolumn{3}{|c|}{22857} \\
\hline
\end{tabular}

\section{GONCLUSIONS}

According to the results obtained in this greenhouse project with practically constant temperature, $\mathrm{pH}$, and humidity conditions, we conclude that the use of potassium polyacrylate as a water retention agent to grow Serrano pepper, combined with this dry hydroponics technique - which does not require fertile soil, because sand and gravel can be perfectly used as support agents - , is an excellent alternative to develop an important agricultural culture in arid and semi-arid areas.

Irrigation water was saved, since only $60 \mathrm{~L}$ of water with nutrients for vegetable gardens were applied, providing an excellent humidity, temperature, and $\mathrm{pH}$ environment. As a result, $100 \%$ of the Serrano pepper plants grew perfectly healthy. We must also highlight that the Serrano pepper was chosen as test plant because it is not locally produced; it is brought from the north of the country, thus increasing its costs. This study will offer local producers an efficient technique in the near future. A $22.85 \mathrm{~kg}$ production of Serrano pepper was obtained, representing a competitive production quota in a market that depends on non-local production. This work aims to consolidate the dry hydroponics technique... but there is still much work to be done. 


\section{ACKNOWLEDGMENTS}

The authors would like to thank Cintya Valerio Cárdenas $(\mathrm{ScD})$ and Patricia de la Cruz Burelo $(\mathrm{ScD})$ for their unconditional support and valuable collaboration in the development of this work. They would also like to thank the Instituto Tecnológico Superior de Villa La Venta for their support for this project.

\section{REFERENGES}

Agrovit (2021). Recuperado 4 de abril de 2021, de http://www.agrobit.com/info_tecnica/alternativos/ horticultura/al_000010ho.htm\#5-Invernaderos\%20con\%20techumbre\%20curva

Científico Mexicano Sergio Rico Velasco. El Padre de la Lluvia Sólida. (s. f.). Metropolis Esceptica. Recuperado 4 de abril de 2021, de https://www.metropolisesceptica.com/

Climatología. (2021). INEGI. Recuperado 4 de abril de 2021, de https://www.inegi.org.mx/temas/climatologia/

Demin, P. E., (2014), Aportes para el mejoramiento del manejo de los sistemas de riego: métodos de riego: fundamentos, usos y adaptaciones. - 1a. ed. - San Fernando del Valle de Catamarca, Catamarca: Ediciones INTA, 28 p.

FAO. (2020). El estado mundial de la agricultura y la alimentación 2020. https://doi.org/10.4060/cb1447es.

Gravital Agency. (s. f.). Sistemas de Cultivo Hidropónico. Puerto Rico Farm Credit. Recuperado 4 de abril de 2021, de https://prfarmcredit.com/sistemas-de-cultivos-hidroponicos/

Hernández-Barajas J., S. Mondragón J., Muñiz O., (2010), Síntesis a nivel de laboratorio de poliacrilatos de sodio de bajo peso molecular para la industria cerámica: comparación de diferentes alternativas de síntesis, Revista Iberoamericana de Polímeros, ISSN-e 0121-6651, Vol. 11, No. 6: 392-406.

Horacio, M. V., Juan, P. P., Moisés, R. M. \& Enrique, V. G. (2010). Fertirrigación de chile serrano con riego por goteo en el sur de Tamaulipas. ISBN: 978-607-425-465-5.

Los hidrogeles de poliacrilato en la agricultura. (7 de mayo 2018). Portal Fruticola. Recuperado 4 de abril de 2021, de website: https://www.portalfruticola.com/noticias/2018/05/07/los-hidrogeles-de-poliacrilatoen-la-agricultura/

Robinson, J. (2014, 24 abril). Chiles perfectos en 4 etapas. Hortalizas. https://www.hortalizas.com/cultivos/ chiles-pimientos/chiles-perfectos-en-4-etapas/\#:\%7E:text=Los\%20chiles\%20se\%20desarrollan\%20 bien,cuando\%20el\%20suelo\%20requiere\%20magnesio.

Zohuriaan-Mehr M. J., Omidian H., Douroudiani S., Kabiri K., (2010), Advances in nonhygienic applications of superabsorbent hydrogel materials. Journal of Material Science 45:57 11-5735. https://doi.org/10.1002/ pc.21046. 